\title{
Extraction and characterization of pectic substances in Myrciaria cauliflora (Jaboticaba sabará) fruit
}

\section{Extração e caracterização de substâncias pecticas no fruto de Myrciaria cauliflora (Jaboticaba sabará)}

\author{
Lirian Moreno \\ Universidade Estadual de Ponta Grossa - UEPG - Ponta Grossa - Brazil \\ lirianmoreno@hotmail.com \\ Revenli Fernanda do Nascimento \\ Universidade Tecnológica Federal do Paraná - UTFPR - Ponta Grossa - Brazil \\ revenli fernanda@hotmail.com \\ Acácio Antonio Ferreira Zielinski \\ Universidade Federal do Paraná - UFPR - Curitiba - Brazil \\ aczielinski@gmail.com \\ Gilvan Wosiacki (in memoriam) \\ Universidade Estadual de Ponta Grossa - UEPG - Ponta Grossa - Brazil \\ wosiacki@uol.com.br \\ Maria Helene Giovanetti Canteri \\ Universidade Tecnológica Federal do Paraná - UTFPR - Ponta Grossa - Brazil \\ canteri@utfpr.edu.br
}

\begin{abstract}
Summary
The jaboticaba is a fruit that is native to Brazil, which has antioxidant activity and is known to have levels of bioactive compounds. This fruit is a berry with a lilac-coloured husk and white flesh; sweet and acid, which justifies its high levels of fresh consumption. The aim of this study was to contribute to the study of a new raw material in small agribusinesses. Jaboticaba- Sabará variety- was fractionated into three parts for pectin analysis: the skin, pulp and juice. The pectic substances of the jaboticaba were analysed. The degree of methoxylation was determined by titration and infrared spectroscopy (FTIR). Pectin extracted from the skin had a higher degree of esterification. The macromolecular composition, determined by high pressure steric exclusion chromatography (HPSEC), discriminated the pectins of high molar mass (skin) and low molecular weight (juice and pulp). The pectin from all the fractions presented homogalacturonan segments with a high degree of esterification, and ramnogalacturan side chains composed of galactose and arabinose. The jaboticaba pectins presented a high content of arabinose in the skin, whilst galactose was only found in traces in the juice, showing different proportions of monosaccharides, similar to commercial samples of apple pectin.
\end{abstract}

Keywords: myrciaria cauliflora, structural compounds, pectin. 


\section{Introduction}

The jaboticaba (Myrciaria cauliflora Berg.) belongs to the Myrtaceae family and is native to southern Brazil, Bolivia, Paraguay and Argentina. This tree can reaches up to 10 meters in height (LE BELLEC; LE BELLEC, 2004).

There are naturally occurring jaboticaba trees in the southwest region of Paraná, southern State of Brazil, in the remnants areas of the Forest Araucaria System, retained as legal protection areas of particular properties. The harvest is still an extractive trade, with the fruit being sold on roadsides in the region; an activity of economic and social importance for poor families (DANNER et al., 2010).

Jaboticaba production is seasonal and is concentrated only in the months of October and November (CLERICI; CARVALHO-SILVA, 2011). It still only has limited commercial trade due to its high perishability, which affects the product's quality and quantity, and which compromises the quality of large volumes of this agricultural product (BRUNINI et al., 2004). Consequently, studies are required regarding conservation methods aimed at shelf life increase of this fruit without affecting its quality (RUFINO, 2008).

The fruit, berry in type, is rounded, dark-purple in colour, and contains between one and four seeds. The skin is thin and fragile and the pulp is white, translucent and sweet with a light acidity (CHIARELLI; NOGUEIRA, VENTURINI-FILHO, 2005). The fruit has good marketing potential due to its organoleptic characteristics and can be used in the manufacture of liqueurs and jams as well as being eaten as table fruit (BRUNINI et al., 2004). According to Souza (1992) and Terci (2004), the jaboticaba fruit has important nutritional and functional properties due to its relatively high concentrations of minerals, especially iron, potassium, magnesium, manganese, phosphorus, calcium and copper. It also has high fibre content in the pulp and the skin is full of anthocyanins with antioxidant power. It is a good source of energy because of its high sugar content (REYNERTSON et al., 2006; CLERICI; CARVALHO-SILVA, 2011; LIMA et al., 2011).

Dietary fibre consists of several compounds that are not digestible by the endogenous secretions of the digestive tract, mainly linked polysaccharides, non-digestible cell wall proteins, lignin, phenolic compounds, phytates, oxalates, modified starch, inulin, oligofructose and chitosan. Although it has a tendency for modification, the classification of dietary fibres also includes the insoluble fraction, composed of cellulose, some hemicellulose and lignin, and the soluble fraction; pectins, gums, mucilages, exudates and some hemicelluloses (FREITAS et al., 2008). Soluble fibres, also found in the fractions of jaboticaba, have important properties that are beneficial to health. Herbstreith and Fox (1998) reported that the effects of pectin on various diseases decreasing the rates of atherosclerosis and blood glucose levels by promoting the complexation of heavy metals and their isotopes; working to reduce body weight; minimizing gastric diseases; facilitating coagulation and wound healing; and have anti-ulcer, anti-nephrosis, anti-nephritis and hypoglycemic properties. The use of lyophilised jaboticaba skin added to the diet of experimental animals (rats) induced increased levels of high density cholesterol (HDL) and increased insulin resistance (LENQUISTE et al., 2012).

Pectin is a soluble fibre found in fruits in varying amounts, with inherent characteristics to each type. It is widely used in candy, drinks and sauces, as a gelling agent, stabiliser and thickener (CANTERI et al., 2012).

The industrialization of jaboticaba production is hampered by the lack of information about its properties for processing. Thus, the knowledge about its structure and the macromolecular formation of its constituents, as well as their rheological properties is essential for quality control, control of shelf life and for the development of equipment and 
processes relevant to this fruit (SATO; CUNHA, 2009).

The study of jaboticaba pectic substances could be ensure its use in dietary preparations, industrial products and the formulation of new products, promoting a better utilization of this fruit through added value. The aim of this study was to determine the yield of pectin fractions from the skin, pulp and juice of Sabará jaboticaba, as well as evaluating its physicochemical (titration), spectroscopic (FTIR), molar mass (HPSEC) and neutral sugars (GLC) characteristics.

\section{Materials and methods}

The pectin production and analysis were carried out in laboratories of Universidade Estadual de Ponta Grossa - UEPG, Ponta Grossa, Brazil.

\subsection{Raw material}

The fruits of the Sabará variety of jaboticaba $(30 \mathrm{Kg})$ were obtained from a commercial orchard located in Lagoa Branca (SP State, Brazil) during the 2008 harvest (2008-2009 marketing year).

\subsection{Processing of powdered pulp, powdered skin and juice}

After being selected according to size and quality by specialized technicians, the jaboticabas fruits were washed, manually sliced and separated with the aid of a spatula into the fractions of seed, skin and pulp. The juice was obtained by centrifuging the whole pulp and immediately frozen at $-5{ }^{\circ} \mathrm{C}$. The pulp-free juice and skin, still with appreciable amounts of sugars, were washed in running water with constant stirring, until depletion of soluble solids $\left(0^{\circ}\right.$ Brix). Subsequently they were dehydrated separately, below $55^{\circ} \mathrm{C}$, to constant weight. This dehydrated material was ground in a Wiley mill, homogenised in ball mills and the sieved fractions $(60 \mathrm{MESH})$ were stored. The products designated as powdered skin and powdered pulp were stored at room temperature $\left(25^{\circ} \mathrm{C}\right)$ in plastic packages. The product designated as juice was frozen $\left(-5{ }^{\circ} \mathrm{C}\right.$ in polyethylene bottles PET). The yield of skin, pulp and juice was determined by the difference between the total initial mass and the mass of the fractions after dehydration.

\subsection{Extraction and separation of the pectin from the skin and pulp}

The powdered skin and the powdered pulp were used as raw materials for the process of acid extraction of the pectin. The extraction and isolation of the pectin followed the methodology of previous studies, with minor modifications (FERTONANI et al., 2006). Approximately five grams of each powder were suspended in about $100 \mathrm{~mL}$ of water and stirred for 10 minutes at $80^{\circ} \mathrm{C}$. To this heated suspension, $100 \mathrm{~mL}$ of $0.1 \mathrm{M}$ nitric acid was added at the same temperature. The mixture was kept at boiling $\left(97^{\circ} \mathrm{C}\right)$ under reflux for 20 minutes. The system was cooled and the resulting suspension was filtered in synthetic fabric (polyester) and stored at $4{ }^{\circ} \mathrm{C}$ for 12 to 24 hours, resulting in the acid extract, the source of pectin. The powder that was exhausted of pectin was left as the main residue.

\subsection{Isolation of pectin from the filtrate and the whole juice}

In terms of the juice, only the soluble pectin was isolated and the acid hydrolysis process described above was not required. The separation of pectin was performed by the addition of the acid extract or juice over two volumes of commercial ethanol with 
graduation between 80 and 96 oGL in a liquid shaker until the formation of gel mesh. After this precipitation, the system was allowed to stand for about 4 hours to form the colloidal pectin structure on the surface, by flotation. This network of pectin was collected in a sieve and separated by filtration in synthetic fabric (polyester), packaged in small filters of the same material, and immersed in acetone and 96 oGL ethanol, and P.A. acetone (30 minutes of each) to remove the excess acid. After further pressing, the pectin remained in an air-circulation oven for evaporation of the solvent at $40^{\circ} \mathrm{C}$ for 12 hours. Later, this dry pectin was manually ground using a Graal. The yield was calculated from the ratio between the amount of pectin obtained and the raw material used in dry basis.

\subsection{Pectin analyses}

A known amount of sample $(250 \mathrm{mg}$ ) was solubilised in $50 \mathrm{~mL}$ of deionised water under constant stirring at $40{ }^{\circ} \mathrm{C}$ until complete dissolution. The free carboxyls of the anhydrous galacturonic acids were neutralised with $0.05 \mathrm{~N} \mathrm{NaOH}$. After saponification (10 $\mathrm{mL}$ of $0.5 \mathrm{~N} \mathrm{NaOH}$ ) for 30 minutes at room temperature, the neutralised carboxyl groups were esterified $(10 \mathrm{~mL} 0.5 \mathrm{~N} \mathrm{HCl})$ to obtain the $\mathrm{mEq}$ values of $\mathrm{NaOH}$, referring to the free and esterified anhydrous galacturonic acids, $\mathrm{mEq}$ and $\mathrm{mEq}$ respectively, from the equations shown in Table 1.

Table 1: Qualitative and quantitative parameters for pectic substances obtained by titration and saponification.

\begin{tabular}{lc}
\hline \multicolumn{1}{c}{ Parameter } & Equation \\
\hline Quantity of mass per milli-equivalent-gram & $\mathrm{Z}=\mathrm{mass} /$ total $\mathrm{mEq}$ \\
Content of anhydrous galacturonic acid residues & $\mathrm{AUA}=17600 / \mathrm{Z}$ \\
Methoxyl content & $\mathrm{MeO}=\left(\mathrm{mEq}{ }^{\prime \prime} \times 31 \times 100\right) / \mathrm{mass}$ \\
Pectin & $\mathrm{Pec}=\mathrm{AUA} \%+\mathrm{MeO} \%$ \\
Neutral fraction & $\mathrm{FN}=100-\mathrm{PEC}$ \\
Degree of esterification & $\mathrm{DE}=(176 / 31) \times(\mathrm{MeO} / \mathrm{AUA})=\mathrm{mEq} /\left(\mathrm{mEq}^{\prime}+\mathrm{mEq}^{\prime \prime}\right)$ \\
\hline
\end{tabular}
Source: own authorship (2010).

For the infrared spectroscopy analyses, tablets were made containing $100 \mathrm{mg}$ of $\mathrm{KBr}$ with 1 to $2 \mathrm{mg}$ of the samples of dried pectin fractions. These were pressed and analysed using a Nicolet 4700 FTIR spectrometer with $2 \mathrm{~cm}-1$ resolution, 60 scans, and the spectrograms were recorded in the $4000-400 \mathrm{~cm}-1$ range. The calculation of the degree of esterification of each sample was made considering the ratio between the area relative to the $1740 \mathrm{~cm}-1$ band (esterified carboxylic groups) and the areas relative to the $1740 \mathrm{~cm}-1$ and $1620 \mathrm{~cm}-1$ bands (esterified and free, respectively). Potassium bromide $(\mathrm{KBr})$ of spectroscopic grade was used as a white for correction of absorption of $\mathrm{CO} 2$ and $\mathrm{H} 2 \mathrm{O}$ (MARCON et al., 2005). Standards of pectin samples with degrees of esterification of 22 and $89 \%$ were purchased from SIGMA (Germany). The molecular weight profile of the fractions was determined by steric exclusion chromatography. Samples at a concentration of $3 \mathrm{mg} \mathrm{mL}-1$ were solubilised in water and filtered under pressure through filters with pore size of $0.2 \mu \mathrm{m}$. The samples were then injected into a steric exclusion chromatograph, model 150C ALC/GPC (Waters, Milford, Massachusetts, USA), with differential refractive index detector, model 2410 (Waters, Milford, Massachusetts, USA), and a for multi-angle laser scattering (MALLS) detector (Wyatt Technology, Santa Barbara, California, USA) (FERTONANI, 2006).

The identification and determination of the relative concentrations of neutral sugars in the pectin samples were taken after derivatisation of alditols by gas chromatographymass spectrometry. The pectins were hydrolysed with $1 \mathrm{M}$ trifluoroacetic acid for 8 hours at $100{ }^{\circ} \mathrm{C}$ and the hydrolysate was brought to evaporation in a hood left on for approximately 24 hours. The free sugars were reduced with $\mathrm{NaBH} 4$ after the $\mathrm{Na}+$ cations were removed 
with resin in the form of acid. Then, the reduced filtrate was dried in a rota-evaporator and washed with methanol to remove boron in the form of trimethyl borate. Subsequently, the samples were acetylated with acetic anhydride and pyridine 1:1 (v:v) leading to the attainment of the alditols acetates, which were extracted with chloroform and washed with $5 \%$ saturated copper sulphate to removal of the pyridine. The samples containing the alditols acetates were analysed by gas-liquid chromatography in a model HP 5890 SII, with a flame ionisation detector and nitrogen as a carrier gas with a flow of $2 \mathrm{~mL}$ to $220^{\circ} \mathrm{C}$. A capillary column $(0.25 \mathrm{~m}$ id $\times 30 \mathrm{~m})$, model DB-210 with a thickness of $0.25 \mathrm{~mm}$ was used (SATO et al., 2011).

\section{Results and discussion}

Cellulose is the predominant structural carbohydrate in the jaboticaba, followed by hemicellulose and then pectin. The amounts can vary, depending on the degree of ripeness, because the partial hydrolysis of pectin and cellulose occur during the ripening of the cellulose (MAGALHÃES; BARROS; FINGER, 1996).

In fruits at the ripened stage and fit for consumption, gravimetric yields of pectin of $4.5 \%$ for skin, $2 \%$ for pulp and $6.0 \%$ for juice have been obtained, indicating that this soluble fibre is found in greater amounts in the isolated liquid portion of the pulp. Dessimoni-Pinto et al. (2011) found lower amounts of fibre in the skin and pulp of jaboticaba, being $8 \%$ and $1.1 \%$, respectively. Lenquiste et al. (2012) quantified values of $20 \%$ for insoluble fibre and $5 \%$ for soluble fibre in lyophilised jaboticaba skin, a value close to that found in the present study. Pectin is usually referred to as soluble fibre (CANTERI et al., 2012) and the results show the considerable level of insoluble fibrous components in the skin.

The pectin extracted from the skin of the fruit was purple in colour due to the anthocyanins (phenolic compounds) that were extracted and precipitated together with the pectin. Rufino (2008) found only $0.44 \%$ of total pectin in jaboticaba pulp, isolated with ethanol after adjusting $\mathrm{pH}$ and enzymatic hydrolysis, and quantified as a percentage of galacturonic acid. In extracting pectin with citric acid under boiling for 30 minutes, the yield was $0.89 \%$. This variation between the values is due to the lack of standardisation of a methodology for the extraction of pectin. In contrast, the measurements of total pectin in the fruit did not vary, and the average content was found to be $618 \mathrm{mg} .100 \mathrm{~g}-1 \mathrm{of}$ pulp.

The titrimetric, spectroscopic and chromatographic characteristics of the samples of pectins obtained experimentally were compared with samples of commercial pectin with high and low degrees of esterification. Quality characteristics were determined using methoxyl (MeO), whose sum represents the percentage of polygalacturonic acid (acid fraction), with the remaining percentage equivalent to the neutral sugars (Table 2).

Table 2: Titrimetric characteristics of experimental jaboticaba pectins and commercial apple pectins $(\%)$

\begin{tabular}{ccccc}
\hline Sample & AUA & MeO & FA & FN \\
\hline Skin & 69.0 & 11.0 & 80.0 & 20.0 \\
Pulp & 65.0 & 7.5 & 72.5 & 27.5 \\
Juice & 59.0 & 8.4 & 67.4 & 32.6 \\
HM & 76.0 & 12.0 & 88.0 & 12.0 \\
LM & 71.0 & 5.9 & 76.9 & 23.1 \\
\hline
\end{tabular}

$\mathrm{HM}$ - pectin of high esterification; LM - pectin of low esterification; AUA - anhydrous galacturonic acid; $\mathrm{MeO}$ - methoxyl content; FA - acidic fraction; FN - neutral fraction; DE - degree of methoxylation Source: own authorship (2010).

A similarity can be observed between the experimental samples and the commercial low esterification pectin sample in terms of galacturonic acid, with average values of 69,65 and $59 \%$ for skin, pulp and juice respectively, well differentiated from the 
$76 \%$ of the commercial samples of pectins with high values of esterification $(\mathrm{HM})$. With respect to the methoxyl content, the results of the samples of the pectin from jaboticaba were closer to the high esterification commercial pectin sample. Therefore, in terms of the levels of polygalacturonic acids and methoxyls, the experimental samples of pectin were closer to the HM samples, but with variable degree of methoxylation, which influenced the gelation. The pectin extracted from the skin showed a higher degree of methoxylation (DE), which justifies why it is used more often in the manufacture of homemade jams, because this process also needs pectin for the formation of gel, besides sugar and acid. The experimental samples extracted from the skin $(77 \%)$ and juice $(68 \%)$ coild be classified as having a high degree of esterification.

The pectins were analysed regarding the degree of esterification and also by infrared spectroscopy, which allowed the identification of the functional groups in different regions of the spectrum. The region of importance for the identification of functional groups of galacturonic acid is between $1000-2000 \mathrm{~cm}-1$, since the free carboxyl groups are absorbed at about $1630 \mathrm{~cm}-1$ and the esterified groups are absorbed at $1750 \mathrm{~cm}-1$. The peaks between 3000 and 2800 are connected to the $\mathrm{C}-\mathrm{H}$ and $\mathrm{CH} 3$ links of the methyl ester groups (MONSOOR, 2005). The most important region for determining the degree of esterification of pectins is that which is directly related to the carboxyl groups, despite the influence of the other groups. Figure $1(A, B, C)$ presents the infrared absorbance spectra of the isolated pectin of the fractions. The average degree of esterification was $67 \%, 55 \%$ and $53 \%$ for pectins extracted from the skin, juice and pulp, respectively - consistent with the conventional value of the high content of commercial pectins with high values of esterification (HM) that were also analysed. Lima et al. (2010) found values of $71 \%$ for pectin extracted from jaboticaba also using the infrared spectroscopy methodology belonging to the group of fruits that produce jams. These average values were relatively lower than those found by titration, which are presented in Table 2.

Figure 1: FT-IR spectroscopic characterization of pectic fractions extracted from jaboticaba. (A) Experimental skin sample pectin, (B) experimental pulp sample pectin (C) experimental juice sample pectin
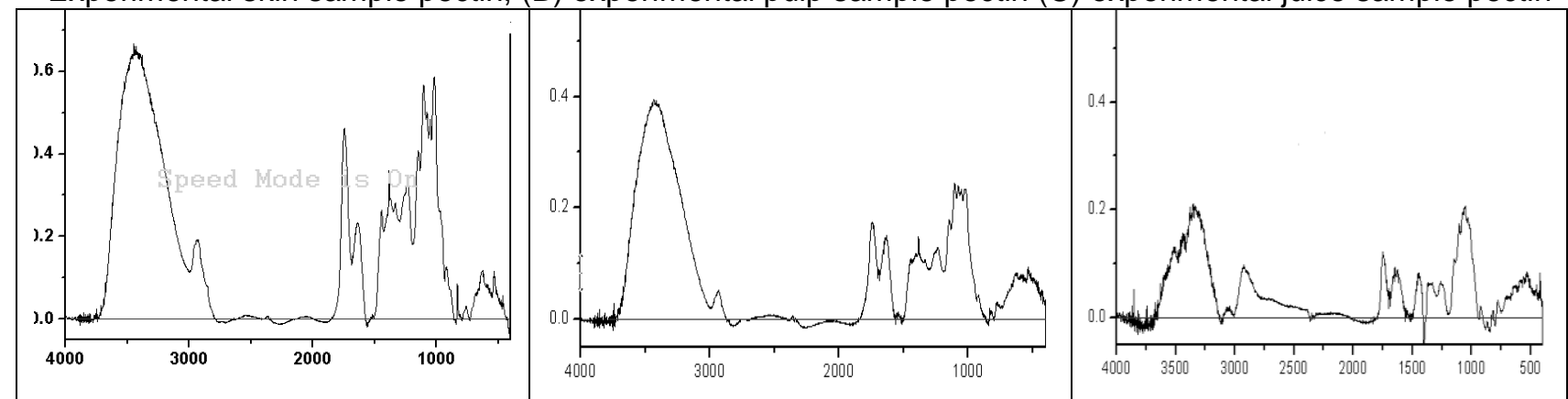

Source: own authorship (2011).

The experimental samples of skin, juice and pulp showed similarities to the commercial sample of high esterification (HMP), in the spectroscopic profile of the degree of esterification calculated as the ratio of peak areas relative to the esterified carboxylic groups and also in the total area of the peaks relative to total carboxylic groups.

The pectin samples were classified as to their dispersion in molecular size with gel permeation by means of chromatographic techniques, being detected by multi-angle light scattering (LS) and refractive index (RI). The pectins were also characterised by gas chromatography with respect to their contents of neutral sugars, reducing them to alditols and confirming their structure by mass spectroscopy.

Figure 2 shows the results of chromatography in HPSEC-MALLS-RI of the three experimental samples of pectin from the jaboticaba in terms and times of retention, considering the light scattering detector (LS-90) and the refractive index. The refractive 
index (blue) supplies a signal proportional to the concentration, while the response of the scattering of light (red) depends primarily on the molecular weight.

Figure 2: Elution profiles by HPSEC-MALLS-RI of skin pectin sample (A), pulp pectin sample (B) and juice pectin sample $(\mathrm{C})$.

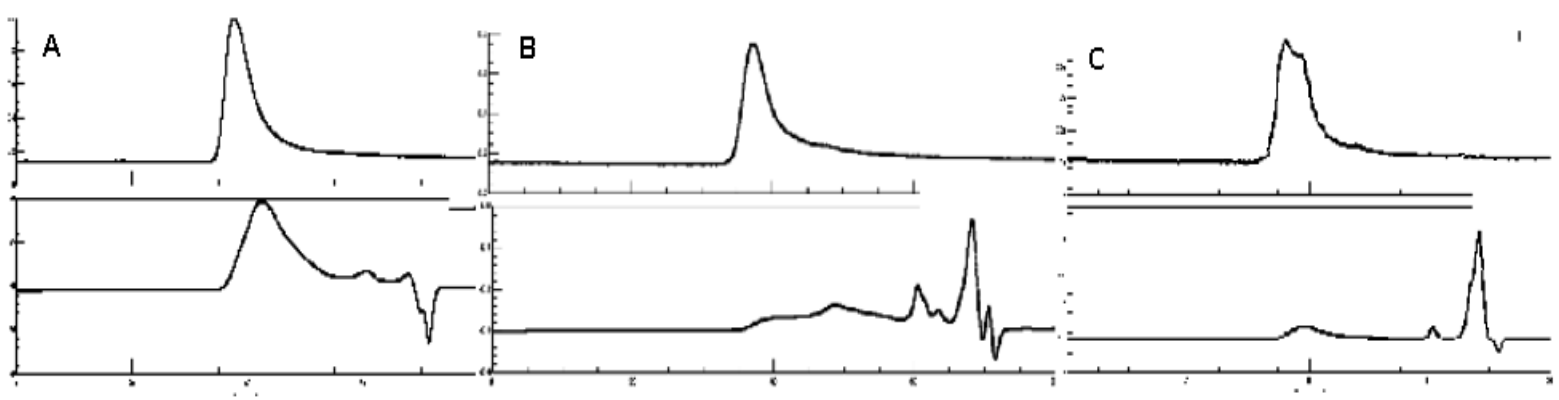

Source: own authorship (2011).

The skin fraction (Figure 2A) shows a heterogeneous profile, probably derived from a mixture of pectic polysaccharides and starch. The presence of a peak, eluting at around 34 minutes and detected with great intensity by light scattering, can be observed that coincides with a high intensity of the refractive index, indicating that it is a high molecular weight component present in high concentration, probably oligomers of pectin or partially hydrolysed pectin.

Figures $2 \mathrm{~B}$ and $3 \mathrm{C}$ also show the presence of a peak around 34 minutes, detected by scattered light, but it coincides with low refractive index intensity, indicating that it is a high molecular weight component present in a low concentration. This peak could be due to the presence of the starch or the result of molecular aggregation. A peak that is evident in the refractive index detector appears around 60 minutes. This coincides with a minimum in the intensity of light scattering, indicating the presence of a lower molecular weight polymer at high concentrations, probably pectin.

Relating the commercial samples to the experimental samples taken from the jaboticaba it can be noted that the commercial samples had a well-differentiated elution profile. These are mainly formed by compounds of high molecular weight that only resemble the molecular profile of pectin extracted from the skin fraction because the pectins extracted from the pulp and juice fractions were mainly composed of compounds of low molecular weight, showing that pectin extracted from different fruits has specific characteristics.

Pinheiro et al. (2008), Santos (2006) and Marcon et al. (2005) also obtained heterogeneous fractions for pectins from the skin of yellow passion fruit, araçá pulp, apple bagasse and mango pulp, demonstrating that it is difficult to obtain a pure pectin from plant materials. Consequently, the exact determination of the molecular weight of a pectin is an extremely difficult task due to the heterogeneous nature of these polysaccharides, which have linear regions and branched side chains, inter-and intramolecular variations, and different patterns of distribution of methyl ester groups along the polygalacturonic chain (KIM; TENG; WICKER, 2005).

Table 3 shows the relative contents of neutral sugars present in the experimental and commercial fractions of pectin as the aggregate fraction of the acidic polysaccharide structure. The proportions of the neutral monosaccharide components in pectin are variable, depending on various factors ranging from the quality of the source to the process and its characteristics. Among all the analysed sugars, the arabinose from the skin presented the highest content $(60 \%)$ while the galactose of the juice only appeared as traces. The rhamnose was homogeneous in the three fractions, with low values of about $1.5 \%$, while arabinose values were consistent with the standard HM (19.6\%) and galactose was lower than the standard HM (49.7\%), both in the pulp and in the juice 
(FERTONANI, 2006). Fucose, a sugar considered to be rare in pectin, presented levels similar to rhamnose, while xylose was found in low levels in all three fractions. Mannose showed intermediate values that were greater than the standards, with higher concentrations in the juice and pulp than in skin, as well as glucose, which had values that were twice as high.

Table 3: Monosaccharide composition of pectin from jaboticaba and commercial apple samples

\begin{tabular}{cccccc}
\multicolumn{7}{c}{$[\mathrm{mg} \cdot \mathrm{g}-1]$} \\
\hline Fraction & Skin & Pulp & Juice & HM & LM \\
\hline Rha & 11 & 14 & 20 & 22 & 37 \\
Fuc & 16 & 28 & 18 & - & - \\
Ara & 63 & 225 & 208 & 196 & 43 \\
Xyl & 9 & 26 & 14 & 76 & 124 \\
Man & 12 & 262 & 280 & 13 & 29 \\
Gal & 44 & 16 & - & 497 & 562 \\
Glc & 169 & 429 & 443 & 197 & 205 \\
\hline
\end{tabular}

$\mathrm{HM}$ - pectin of high esterification; LM - pectin of low esterification; (-) - non-detectable quantities; Rha - rhamnose; Fuc - fucose; Ara - arabinose; Xyl - xylose; Man - mannose; Gal - galactose; Glc glucose

Source: own authorship (2014).

The comparison of the sugars from the experimental samples with those of the commercial samples contributed to the perception of great diversity related to several different factors (FERTONANI, 2006).

Table 4 presents the combined results of the titration method (which gives the proportions of the acidic fraction) with the chromatographic method (which makes it possible to establish the proportions of each of the neutral sugars). This table contains the relative values for the methoxyl groups just to round up the values to $100 \%$.

Table 4: Relative percentage proportion of neutral and acid sugars identified acids in the pectin samples of the jaboticaba fractions

\begin{tabular}{cccccc}
\hline Fraction & Skin & Pulp & Juice & HM & LM \\
\hline AUA & 69 & 65 & 59 & 76 & 71 \\
MeO & 11 & 7.5 & 8.4 & 12 & 5.9 \\
Rha & 0.23 & 0.39 & 0.63 & 0.23 & 0.84 \\
Fuc & 0.32 & 0.78 & 0.56 & - & - \\
Ara & 12.6 & 6.2 & 6.6 & 2.3 & 0.99 \\
Xyl & 0.2 & 0.7 & 0.46 & 0.9 & 2.85 \\
Man & 2.4 & 7.1 & 9 & 0.16 & 0.66 \\
Gal & 0.88 & 0.44 & - & 6 & 13 \\
Glc & 3.4 & 11.8 & 14 & 2.4 & 4,7 \\
\hline \multicolumn{6}{c}{ Source: own authorship (2014). }
\end{tabular}

The contents of galacturonic acid and methoxyl groups characterised the experimental samples extracted from skin, pulp and juice with a high degree of esterification. The relationship between galacturonic acid and rhamnose indicates how many acid molecules form part of the chain, per unit of rhamnose. The values found for the pectins of skin, pulp and juice were 300:1, 166:1, and 93:1, respectively. For the commercial pectins, values of $330: 1$ and $84: 1$ to $330: 1$ were found for the pectin of high and low degrees of esterification, respectively, which means there is one residue of rhamnose for each 330 residues of galacturonic acid in pectin of high esterification, for example. The calculation of the ratio of rhamnose to galacturonic acid, suggests that pectins extracted from fractions of jaboticaba could consist mainly of smooth regions that are rich in polygalacturonic acid, typically found in pectins of the middle lamella (MCCANN; ROBERTS, 1991).

\section{Conclusions}


The highest yield of pectin was obtained from the juice, followed by the skin, and then by the solid fraction of the pulp. The pectic fractions, called pectin from the skin, pulp and juice of the jaboticaba were soluble in acid. The pectins from the skin, juice and pulp were mainly composed of segments of homogalacturonans with a high degree of esterification (DE 67\%, 55\% and 53\%) and rhamnogalacturonans with side chains consisting mainly of mannose and arabinose, especially frucose, not normally found in the pectins of other fruits. The experimental samples showed different proportions of monosaccharides as well as the commercial samples.

\section{Acknowledgements}

This work was supported by CAPES Fondation (Proc. 99999.006882/2014-05) and CNPq (Proc. 487621/2012-3). Also, the authors thank their respective Institutions.

\section{References}

BRUNINI, M. A. et al. Influência de embalagens e temperatura no armazenamento de jabuticabas (Myrciaria jaboticaba (Vell) Berg) cv 'SABARÁ'. Ciência e Tecnologia de Alimentos, Campinas, v. 24, n. 3, p.378-383, jul./set. 2004.

CANTERI, M. H. G. et al. Pectina: da matéria-prima ao produto final. Polímeros, São Carlos, v. 22, n. 2, p. 149-157, apr. 2012.

CHIARELLI, R. H. C.; NOGUEIRA, A. M. P.; VENTURINI-FILHO, W. G. Fermentados de jabuticaba (myrciaria cauliflora Berg): processos de produção, características físicoquímicas e rendimento. Brazilian Journal of Food Technology, Campinas, v. 8, n. 4, p. 277-282, out./dez. 2005.

CLERICI, M. T. P. S.; CARVALHO-SILVA, L. B. Nutritional bioactive compounds and technological aspects of minor fruits grown in Brazil. Food Research International, v. 44, n. 7, p. 1658-1670, aug. 2011.

DANNER, M. A. et al. Diagnóstico ecogeográfico da ocorrência de jabuticabeiras nativas no sudoeste do Paraná. Revista Brasileira de Fruticultura, Jaboticabal-SP, v. 32, n. 3, p. 746-753, set. 2010.

DESSIMONI-PINTO, N. A. V. et al. Jaboticaba peel for jelly preparation: an alternative technology. Ciência e Tecnologia de Alimentos, Campinas, v. 31, n.4, p. 864-869, oct./dec. 2011.

FERTONANI, H. C. R. Estabelecimento de um modelo de extração ácida da pectina de bagaço de maçã. 2006. 79 f. Dissertarion (MA in Science and Food Technology) postgraduate program in Science and Food Technology, Universidade Estadual de Ponta Grossa, Ponta Grossa.

FERTONANI, H. C. R. et al. Influência da concentração de ácidos no processo de extração e na qualidade de pectina de bagaço de maçã. Semina: Ciências Agrárias, Londrina, v. 27, v. 4, p. 599-612, oct./dec. 2006.

FREITAS, S. C. et al. Procedimento operacional padrão para determinação de fibras solúvel e insolúvel. Rio de Janeiro: Embrapa Agroindústria de Alimentos, 2008. 
HERBSTREITH and FOX. Pectins in Preventive Nutrition and Therapy. Available at: <http://www.herbstreith-fox.de/en/informative-literature/informative-literature-from-rd-andtech-application.html> Vitafood Congress. 1998.

KIM, Y.; TENG, Q.; WICKER, L. Action pattern of Valencia orange PME deesterification of high methoxyl pectin and characterization of modified pectin. Carbohydrate Research, $v$. 12, n. 17, p. 2620-2629, dec. 2005.

LE BELLEC, F.; LE BELLEC, V. À la découverture des fruits des Antilles. França: PLB Éditions, 2004, 128f. Available at: <http://caribfruits.cirad.fr/fruits_des_antilles/jaboticaba>. Acess: 18 aug. 2013.

LENQUISTE, S. A. et al. Freeze-dried jaboticaba peel added to high-fat diet increases HDL-cholesterol and improves insulin resistance in obese rats. Food Research International, v. 49, p. 153-160, nov. 2012.

LIMA, A. J. B.; CORRÊA, A. D.; DANTAS-BARROS, A. M.; NELSON, D. L.; AMORIM, A. C. L. Sugars, organic acids, minerals and lipids in jaboticaba. Revista Brasileira de Fruticultura, Jaboticabal-SP, v. 33, n. 2, p. 540-550, jun. 2011.

LIMA, M. S. et al. Fruit pectins: A suitable tool for screening gelling properties using infrared spectroscopy. Food Hydrocolloids, v. 24, n. 1, p. 1-7, jan. 2010.

MAGALHÃES, M. M.; BARROS, R, S.; FINGER, F. L. Changes in structural carbohydrates in developing fruit of Myrciaria jaboticaba. Scientia Horticulturae, v. 66, n. 1-2, p. 17-22, set. 1996.

MARCON, M. V.; VRIESMANN, L. C.; WOSIAKI, G.; CARNEIRO, E. B.; PETKOWICZ, C. L. O. Pectins from apple pomace. Polímeros, São Carlos, v. 15, n. 2, p. 127-129, apr./jun. 2005.

McCANN, M. C.; ROBERTS, A. Architecture of the primary cell wall. In: LLOYD, C. W (Org.). The Cytoskeletal Basis of Plant Growth and Form. San Diego: Academic Press, 1991.

MONSOOR, M. A. Effect of drying methods on the functional properties of soy hull pectin. Carbohydrate Polymers, v. 61, n. 3, p. 362-367, aug. 2005

PINHEIRO, E. R. et al. Optimization of extraction of high-ester pectin from passion fruit peel (Passiflora edulis flavicarpa) with citric acid by using response surface methodology. Bioresource Technology, v. 99, n. 13, p. 5561-5566, sep. 2008.

REYNERTSON, K. A. et al. Bioactive desides and anthocyanins from jaboticaba (Myrciaria cauliflora). Journal of Natural Products, v. 69, n. 8, p. 1228-1230, aug. 2006.

RUFINO, M. S. M. Propriedades funcionais de frutas tropicais brasileiras não tradicionais. 2008. $273 \mathrm{f}$. Thesis ( $\mathrm{PhD}$ in Phytotechnology) - postgraduate program in Phytotechnology, Universidade Federal Rural do Semi-Árido, Mossoró.

SANTOS, M. S. Caracterização físico-química e aproveitamento tecnológico do araçá vermelho (Psidium cattleianum S.). 2006. 173 f. Dissertation (MA in Science and 
Food Technology) - postgraduate program in Science and Food technology, Universidade Estadual de Ponta Grossa, Ponta Grossa.

SATO, A. C. K.; CUNHA, R. L. Effect of particle size on rheological properties of jaboticaba pulp. Journal of Food Engineering, v. 91, n. 1, p. 566-570, apr. 2009.

SATO, M. F. et al. Chemical and instrumental characterization of pectin from dried pomace of eleven apple cultivars. Acta Scientiarum Agronomy, Maringá, v. 33, 2011, p. 383-389, jul./set. 2011.

SOUZA, R. B. Acúmulo e distribuição de Minerais no fruto de Jaboticaba (Myrciaria jaboticaba Berg cv. Sabará) em Desenvolvimento. 1992. 62 f. Dissertation (MA in Plant Physiology) - postgraduate program in plant physiology, Universidade Federal de Viçosa, Viçosa.

TERCI, D. B. L. Aplicações Analíticas e Didáticas de Antocianinas Extraídas de Frutas. 2004. 213f. Thesis (PhD in Chemical Analysis) - postgraduate program in Chemical Analysis, Universidade Estadual de Campinas, Campinas. 